\title{
Data Acquisition for Wind Turbine Design and Analysis using Arduino
}

\section{Ehab Bani Hani*}

Department of Mechanical Engineering, Australian College of Kuwait, Kuwait

\begin{abstract}
Wind turbines are widely used nowadays as devices for renewable energy utilization that is the wind energy. Before designing the wind turbine, many parameters must be measured for the best selected design. Theses parameters include wind speed, wind speed variation with height, power generation etc. Thus the use of computer software such as Arduino is very helpful tool to achieve such a task. This work is aimed to show the application of Arduino to measure the environmental parameters that affect the power generation of wind turbines such as wind speed. The code used to programme the instruments and sensors are shown. The power measured experimentally based on the measured parameters are shown.

Results show that Arduino can get accurate measurements. And by using suitable software it provides full calculations of the design parameters. The data are presented in an excel spread sheet where it can be used later for the design procedure. The use of Arduino requires writing codes for data acquisition and processing. Critical data for wind power calculations are shown. The height of $15 \mathrm{~m}$ is achieved and the wind speed, voltage, current and power is calculated. By comparing the data obtained by Arduino to published data for Kuwait the results found comparable. The Arduino value for wind speed in June at height of $10.0 \mathrm{~m}$ is $8.0 \mathrm{~m} / \mathrm{s}$, however, the average value of wind speed in June is $5.7 \mathrm{~m} / \mathrm{s}$ and the maximum value of wind speed in June is $20.0 \mathrm{~m} / \mathrm{s}$ at the same height.
\end{abstract}

Keywords: Arduino; Wind turbine; Data acquisition

\section{Introduction}

Wind energy is considered one of the most sustainable sources of power generation. It is also considered the cleanest for the absence of any pollution activity or emission which could lead to the increase in the global warming. Another advantage of utilizing wind power is that it is widely available, and can be considered an alternative to the finite power sources such as fossil fuel, which can cause harm to both living beings and the environment [1].

To make it feasible to harvest energy from winds, wind speed should blow at relatively high values. This can be achieved when going for high distances from ground. Thus it is important to measure the wind speed at different heights before designing and installing the wind turbine.

The yearly estimated wind speed generally obtained in Kuwait from commonly used standard heights 10-30 meters is considered to be low with a velocity of 5 meters per second, but fairly usual for that level. During a month time period, it is found that the wind speed is at its peak in both June and July, with wind speeds of $6.7 \mathrm{~m} / \mathrm{s}$ and 6.2 $\mathrm{m} / \mathrm{s}$ respectively. Lowest wind speeds in a month period were during October with a wind speed of $4 \mathrm{~m} / \mathrm{s}$. Referencing the airport wind gust data, it is shown that during a long period of 56 years, the average range of wind speed from March to August is determined to be approximately $5.7 \mathrm{~m} / \mathrm{s}$ in a 6 month time period.

Maximum wind speed during monthly periods at 30 meters resulted in wind velocity of $35.1 \mathrm{~m} / \mathrm{s}$, but the mean monthly highest wind speed resulted to be $23.4 \mathrm{~m} / \mathrm{s}$. During May in 1968, the highest wind speed measurement was registered, the maximum wind gust was found to be $44.5 \mathrm{~m} / \mathrm{s}$, which is the highest wind speed value ever in Kuwait history [2]. The need of wind speed is for the calculations of the power available in the wind, which can be calculated using eqn. (1),

$$
\text { Power }=\frac{1}{2} \rho A v^{3}
$$

Where, $v$ is the velocity of the wind $(\mathrm{m} / \mathrm{s})$ and $\rho$ is the air density $\mathrm{kg} / \mathrm{m}^{3}, A\left(\mathrm{~m}^{2}\right)$ is the cross-sectional area of the wind turbine that the wind passes through. Thus the wind speed and its measurement play an important factor in calculating the amount of energy that can be extracted from the wind.

For the purpose of estimating the wind speed, many researchers used soft computing technologies to estimate [3]. Other researchers [2] predicted the power generation from winds by using artificial neural network. Thus the use of computer in research and technology is wide as it gives predictions, manipulations, and flexibility in handling with the data being collected and/or processed. So it is used not only in wind speed and power calculations but also in many applications in engineering field such as fluid mechanics, pipe flow, and many other applications [4-6], this including different software such as computer aided design (CAD) and other software [7,8].

In engineering education students should be exposed to use technology and computer software. Literature shows that students can use android device to improve student's engagement in programming [9] as well as to design electro mechanical systems [10].

In this study the wind speed is measured using Arduino coding and the corresponding power generated is estimated. Arduino is used to transfer and manipulate the data comes from sensors and transmitters and processed by receivers. The experiment is conducted in Kuwait in June/2017. Similar data obtained for Kuwait on the same month, for the values of average and maximum wind speed are used for comparison.

*Corresponding author: Ehab Bani Hani, Department of Mechanica Engineering, Australian College of Kuwait, Kuwait, Tel: +965 1828225; E-mail: e.hani@ack.edu.kw

Received November 15, 2017; Accepted November 23, 2017; Published November 27, 2017

Citation: Hani EB (2017) Data Acquisition for Wind Turbine Design and Analysis using Arduino. Adv Robot Autom 7: 180. doi: 10.4172/2168-9695.1000180

Copyright: (C 2017 Hani EB. This is an open-access article distributed under the terms of the Creative Commons Attribution License, which permits unrestricted use, distribution, and reproduction in any medium, provided the original author and source are credited. 
The following section explains the application of Arduino in wind turbine engineering design.

\section{Components of the Testing Device}

Arduino is very helpful tool in many applications [11-13]. The device used in this study has the following components.

\section{Bread board}

Breadboards are used to build varies types of circuit according to the system and hardware requirements using resistors and capacitors etc. Also used to extend power source lines as only two points are available in microcontroller/Arduino UNO3 for $5 \mathrm{v}(+)$ and ground (-).

\section{V battery snap and 9V battery}

To power microcontroller, battery is used in addition to battery connector. Battery can be replaced whenever needed and connector is used to attach battery with microcontroller.

\section{Current sensor (ACS712)}

This sensor measures the electrical current (amps) running through the circuit (via wires) by connecting sensor points on one side of the circuit either positive or negative junction.

\section{Wind speed sensor (anemometer)}

The purpose of anemometer device/wind speed sensor is to capture wind from environment and allowing rotation of its blades/wings at certain speed, which produces signal (voltage range $7 \mathrm{v}$ to $24 \mathrm{v} \mathrm{dc}$ ), which is then converted and measured by microcontroller or mini PCs.

\section{Barometric pressure sensor}

BMP180 is a barometric pressure sensor (Figure 1). It features are measuring pressure in units of $(\mathrm{Pa})$, pressure is used to determine altitude from pressure graph above sea level and also provides the corresponding temperature readings to the microcontroller.

\section{Tx transmitter and $\mathrm{Rx}$ receiver}

They are wireless data transmitter and receiver, which allow transmitting data from microcontroller board to another board with the help of signal data transmission.

\section{Resistors}

Resistors resist the flow of electricity and the higher the value of the resistor, the more it resists and the less electrical current will flow through it (Figure 2).

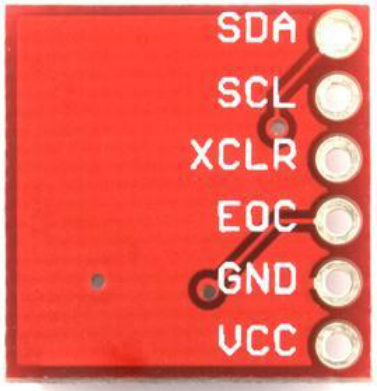

Figure 1: Barometric pressure sensor.

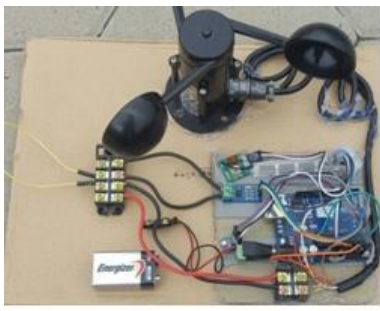

Figure 2: Transmitter Unit (Tx).

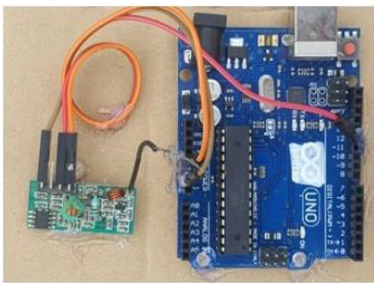

Figure 3: Receiver unit (Rx).

\section{Voltage divider}

It is used to measure voltage $24 \mathrm{v} \mathrm{dc}$, which will be produced by the generator. Microcontroller are capable of receiving and sending the signal within the range $(0 \mathrm{v}-5 \mathrm{v})$ so, to step down $24 \mathrm{v}$ to $5 \mathrm{v}$ circuit must be build consisting of resistors (Figure 3 ).

\section{Methodology}

An inflated body that can reach heights up to $30.0 \mathrm{~m}$ is used. Different sensors are attached to the body. The inflated body has two Arduino boards one is for receiving signal data using Rx (Receiver) codes attached for $\mathrm{Rx}$ and also the wiring circuit. The second board is for transmitting data using $\mathrm{Tx}$ (Transmitter) and measuring wind speed, current, altitude, voltage using different sensors. The full circuit is shown in Figure 4. Arduino software 1.6.8 is installed depending on the platforms software that will be used (windows in this study).

As soon it starts Arduino board is connected Via USB cable to the device or to the system. Arduino have many different models which also can be selected by going to the tools and click on boards. From boards list Arduino model can be selected. It should be mentioned that the type of Arduino board is automatically selected by the software when it detects or connected to the system by default. Now Board is ready to be program by Defining each pins present in the board as output or input mode. Input/output mode specifies a reference voltage (which is 5 voltages in this study) to the power sensors and to receive data. This is to measure or to operate certain devices like motors, speakers, relays, etc.

Arduino is an open source platform. It is cheap and easy to install. Arduino board can read inputs on a sensor, can be used to give output and operate any hardware. Developer or programmer can guide board by set of instructions (programming code) arrangement of focusing to the microcontroller on the board. To do overall one can use the Arduino programming software and the Arduino Programming Integrated development environment (IDE), in perspective of Planning.

The transmitter unit is sending the information about height, wind speed, current, and voltage to the system where excel sheet is prepared. The results are obtained in excel spread sheet containing all of the information required. The power generated from the wind is calculated by eqn. (2) 


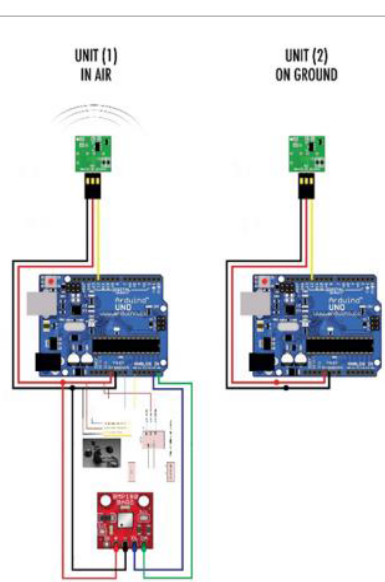

Figure 4: Full circuit connected to the inflated body for data acquisition and the circuit connected to the device on ground for data processing.

\section{Power $=I V$}

Where I is the current (Amp) and V is the voltage (Volt) that are created in an electrical generator connected to the inflated body.

\section{Arduino Codes}

The Arduino code is long as the code should be written for each sensor and parameter to be measured. Sample of the transmitter coding is presented here for wind sensors (anemometer) in addition to the receiving code.

\#include $<$ VirtualWire.h $>$ \#include $<$ SFE_BMP180.h $>$ \#include $<$ Wire.h $>$

// You will need to create an SFE_BMP180 object, here called "pressure":

SFE_BMP180 pressure; double baseline; // baseline pressure

int sample=0; void setup () \{ Serial.begin(9600); delay(100);

pinMode (A0, INPUT);// pinMode (A1, INPUT); pinMode (A2, INPUT); pinMode(13,OUTPUT);

vw_set_ptt_inverted(true); // vw_set_tx_pin(12); vw_ setup(4000);// speed of data transfer Kbps // Get the baseline pressure:

if (pressure.begin()) Serial.println("BMP180 init success");

else \{ Serial.println("BMP180 init fail (disconnected?) \n\n");

\}baseline = getPressure(); Serial.print("baseline pressure: "); Serial.print(baseline); Serial.println(" mb"); constintanalogIn = A1; intmVperAmp = 100; // use 185 for $5 \mathrm{~A}$ Module, 100 for $20 \mathrm{~A}$ Module and 66 for 30A Module intRawValue $=0$; intACSoffset $=2500$;

$/ /$ double Voltage $=0$; double Amps $=0$; int Vin $=24$; intVout $=3.91$;

int Ratio=Vin/Vout; $\quad$ void loop()

$\{$ doublea,P; RawValue $=$ analogRead $(\mathrm{A} 1) ;$ Voltage $=($ RawValue $/$ 1023.0 $) * 5000 ; / /$ Gets you mV Amps $=(($ Voltage - ACSoffset $) /$ mVperAmp); Serial.print("Raw Value = " ); // shows pre-scaled value Serial.print(RawValue); Serial.print("It $\mathrm{mV}=$ "); // shows the voltage measured Serial.print(Voltage,3); // the '3' after voltage allows you to display 3 digits after decimal point Serial.print("\t Amps = "); // shows the voltage measured Serial.println(Amps,3); // the ' 3 ' after voltage allows you to display 3 digits after decimal point delay(2500); //Readings

//Wind floatWind_speed; Wind_speed $=((($ analogRead $\left.(\mathrm{A} 0)) / 1023.0)^{\star} 32.4\right)-3.0$ );
Serial.print("Wind Speed= "); Serial.print( Wind_speed); Serial. println(" m/s");

\section{The Receiver Coding is as follows:}

\#include $<$ VirtualWire.h $>$ void setup()

\{ Serial.begin(9600); vw_set_ptt_inverted(true); // Required for DR3100 vw_set_rx_pin(12); vw_setup(4000); // Bits per sec

pinMode(13, OUTPUT); vw_rx_start(); // Start the receiver PLL running

\} void loop() \{ uint8_t buf[VW_MAX_MESSAGE_LEN]; uint8_t buflen = VW_MAX_MESSAGE_LEN; if (vw_get_message(buf, \&buflen)) // Non-blocking

$$
\{\text { for (inti }=0 ; \mathrm{i}<\text { buflen;i++) }\{\text { Serial.write(buf[i]); }\}
$$

\section{Results and Discussion}

The actual results are extracted to Arduino using a computer. Anemometer is device (sensor) used to measure the wind speed at different heights. Wind turbine has a generator which rotates as wind is blowing to generate electricity. The extracted Arduino data is then exported to excel spread sheet where figures can be made. Table 1 show the data obtained using Arduino, where this data is used to create Figure 5. In Figure 5 the power generated as function of wind speed is shown. In Figure 6 the power generation as function of height is shown.

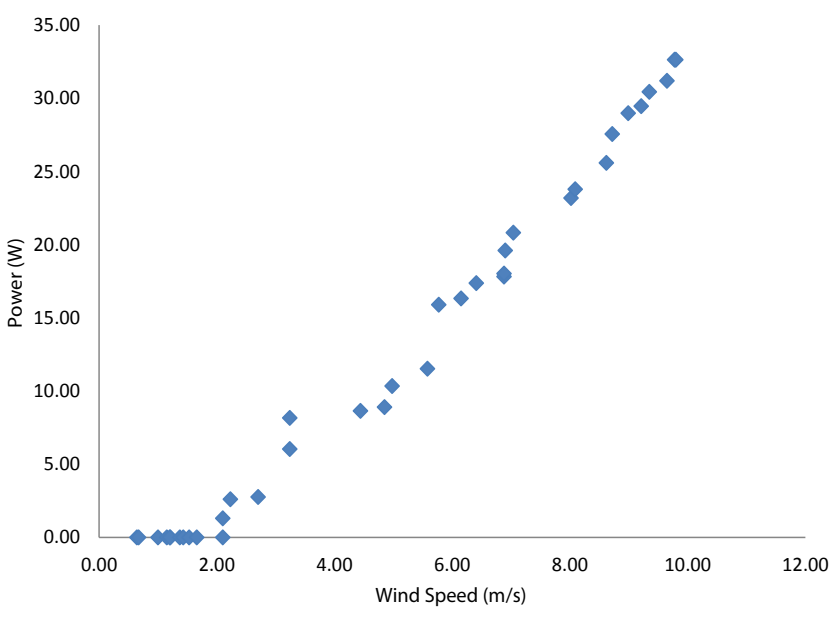

Figure 5: Power generated as function of wind speed using arduino.

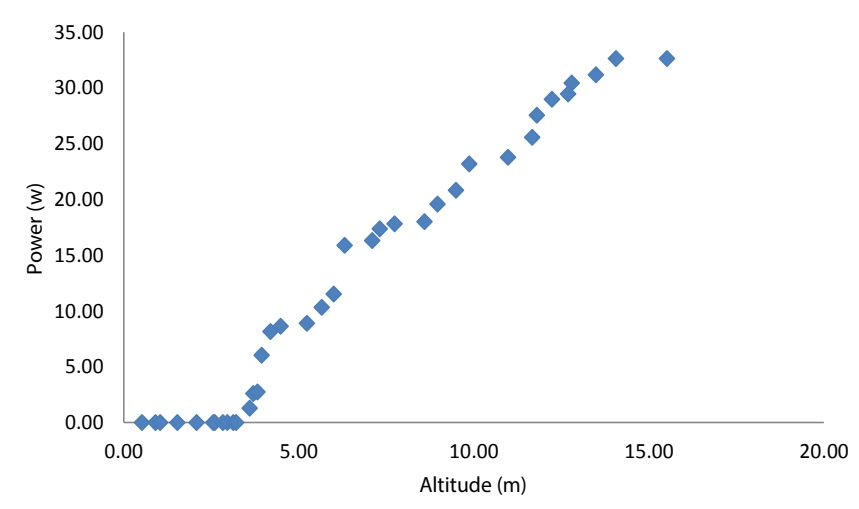

Figure 6: Power generated as function of altitude using arduino. 
Citation: Hani EB (2017) Data Acquisition for Wind Turbine Design and Analysis using Arduino. Adv Robot Autom 7: 180. doi: 10.4172/21689695.1000180

Page 4 of 5

The information in Figure 6 is very important for those who want to design and build a real wind turbine on large scale.

To validate the results obtained using Arduino, the Arduino outcomes are of same trend with any wind turbine analysis procedure, for example the increase in the power output with increasing the wind speed (Figure 5) and the increase of wind speed as a result of increasing height from ground which is clearly presented in Figure 6.

To check the accuracy of the data, a previously relevant published data are used for comparison. It is found that the results obtained by Arduino are comparable to the data obtained experimentally by using one or two heights only. For example the wind speed obtained by Arduino is $8.0 \mathrm{~m} / \mathrm{s}$ at height of $10.0 \mathrm{~m}$ compared to the average value of $5.7 \mathrm{~m} / \mathrm{s}$ at the same height. The maximum wind speed is $20.0 \mathrm{~m} / \mathrm{s}$ at this height. Thus the results obtained are within the range and comparable to the average value keeping in mind that the published data were only at two heights which makes the manipulation inaccurate.

Moreover, if a velocity profile with height is needed it cannot be achieved using only two data points, however, the Arduino results provide the wind speed at each height with small intervals continuously.
The small differences in the values are attributed to old estimation of the wind speed published data which occurred in 2005 [2] and used average not instant values.

\section{Discussion}

It can be clearly seen from Table 1 that the height, pressure, and wind speed measurements can be obtained directly using suitable sensors and Arduino boards. Applying some simple correlations to estimate the wind power and the electrical power generated a full engineering analysis is easily achieved where Arduino is easily programmed to do all of the required calculations. Installing the Arduino to a system such personal computer in this study) it is easily to obtain the data automatically in tables where it can be used later to estimate other parameters and create charts such as Figure 5 and 6.

The use of Arduino is very helpful in such an engineering application which is the design and build of wind turbines. Where the necessary parameters to complete the design are measured and/or calculated depending on the independent variable which is the height in this case. This is more accurate than using soft computing technologies

\begin{tabular}{|c|c|c|c|c|c|c|c|}
\hline Pressure & Altitude & Wind Speed & Voltage & Current & Power & Ampere hour & Power hour \\
\hline$(\mathrm{mb})$ & $(\mathrm{m})$ & $(\mathrm{m} / \mathrm{s})$ & (v) & (A) & (W) & (Ah) & (Wh) \\
\hline 1006.63 & 0.52 & 0.64 & 0.00 & 0.07 & 0.00 & 0.00 & 0.00 \\
\hline 1006.14 & 0.91 & 0.67 & 0.00 & 0.12 & 0.00 & 0.17 & 4.08 \\
\hline 1005.97 & 1.04 & 1.00 & 0.00 & 0.17 & 0.00 & 0.19 & 4.56 \\
\hline 1005.97 & 1.53 & 1.15 & 0.00 & 0.22 & 0.00 & 0.22 & 5.28 \\
\hline 1005.90 & 2.08 & 1.21 & 0.00 & 0.56 & 0.00 & 0.31 & 7.44 \\
\hline 1005.72 & 2.56 & 1.20 & 0.00 & 0.56 & 0.00 & 0.29 & 6.96 \\
\hline 1005.73 & 2.60 & 1.37 & 0.00 & 0.61 & 0.00 & 0.24 & 5.76 \\
\hline 1005.67 & 2.83 & 1.43 & 0.00 & 0.95 & 0.00 & 0.36 & 8.64 \\
\hline 1005.67 & 2.96 & 1.53 & 0.00 & 1.00 & 0.00 & 0.24 & 5.76 \\
\hline 1005.62 & 3.13 & 1.66 & 0.00 & 1.00 & 0.00 & 0.26 & 6.24 \\
\hline 1005.61 & 3.21 & 2.10 & 0.00 & 1.05 & 0.00 & 0.21 & 5.04 \\
\hline 1005.60 & 3.60 & 2.10 & 1.24 & 1.05 & 1.30 & 1.21 & 29.04 \\
\hline 1005.58 & 3.70 & 2.23 & 2.49 & 1.05 & 2.61 & 0.66 & 15.84 \\
\hline 1005.55 & 3.82 & 2.70 & 2.51 & 1.10 & 2.76 & 1.34 & 32.16 \\
\hline 1005.55 & 3.94 & 3.24 & 4.65 & 1.30 & 6.05 & 1.41 & 33.84 \\
\hline 1005.54 & 4.19 & 3.24 & 5.87 & 1.39 & 8.16 & 2.33 & 55.92 \\
\hline 1005.52 & 4.48 & 4.44 & 6.22 & 1.39 & 8.65 & 2.33 & 55.92 \\
\hline 1005.51 & 5.23 & 4.85 & 6.40 & 1.39 & 8.90 & 2.34 & 56.16 \\
\hline 1005.44 & 5.66 & 4.98 & 7.18 & 1.44 & 10.34 & 3.44 & 82.56 \\
\hline 1005.30 & 6.00 & 5.58 & 8.00 & 1.44 & 11.52 & 4.46 & 107.04 \\
\hline 1005.26 & 6.31 & 5.77 & 10.67 & 1.49 & 15.90 & 4.44 & 106.56 \\
\hline 1005.23 & 7.10 & 6.15 & 10.96 & 1.49 & 16.33 & 4.49 & 107.76 \\
\hline 1005.22 & 7.31 & 6.41 & 11.66 & 1.49 & 17.37 & 3.37 & 80.88 \\
\hline 1005.15 & 7.74 & 6.88 & 11.80 & 1.51 & 17.82 & 3.20 & 76.80 \\
\hline 1005.05 & 8.59 & 6.88 & 11.94 & 1.51 & 18.03 & 3.23 & 77.52 \\
\hline 1004.95 & 8.96 & 6.90 & 12.81 & 1.53 & 19.60 & 3.26 & 78.24 \\
\hline 1004.91 & 9.49 & 7.04 & 13.61 & 1.53 & 20.82 & 3.62 & 86.88 \\
\hline 1004.85 & 9.87 & 8.02 & 15.16 & 1.53 & 23.19 & 3.53 & 84.72 \\
\hline 1004.80 & 10.98 & 8.09 & 15.25 & 1.56 & 23.79 & 3.56 & 85.44 \\
\hline 1004.67 & 11.67 & 8.62 & 16.30 & 1.57 & 25.59 & 3.86 & 92.64 \\
\hline 1004.62 & 11.80 & 8.72 & 17.34 & 1.59 & 27.57 & 4.17 & 100.08 \\
\hline 1004.59 & 12.23 & 8.99 & 18.23 & 1.59 & 28.99 & 4.21 & 101.04 \\
\hline 1004.57 & 12.69 & 9.21 & 18.53 & 1.59 & 29.46 & 4.66 & 111.84 \\
\hline 1004.47 & 12.80 & 9.35 & 18.79 & 1.62 & 30.44 & 4.73 & 113.52 \\
\hline 1004.37 & 13.49 & 9.65 & 19.14 & 1.63 & 31.20 & 4.56 & 109.44 \\
\hline 1004.30 & 14.06 & 9.78 & 19.43 & 1.68 & 32.64 & 4.49 & 107.76 \\
\hline 1004.13 & 15.2 & 9.80 & 19.43 & 1.68 & 32.64 & 4.50 & 108.00 \\
\hline
\end{tabular}

Table 1: Data obtained using Arduino 
Citation: Hani EB (2017) Data Acquisition for Wind Turbine Design and Analysis using Arduino. Adv Robot Autom 7: 180. doi: 10.4172/21689695.1000180

to extrapolate the parameters using complicated correlations with a certain percentage of error.

Measuring the wind speeds at different height to calculate the expected power generation of a wind turbine is one application of Arduino. This study can be used in engineering education in colleges and universities where the students have to use software and hardware. Many engineering applications where computers are part of the education processes can be studied. For example Arduino can be used to measure the temperature, air stream speed, and humidity in drying certain wet media.

Simple equations can be inserted in excel sheet such as ones to calculate the evaporation rate and continuous calculations can be obtained. Other sensors can be used to measure the weight as function of time of the wet media to show the change in weight of the wet media. All of these steps can be made easy by using suitable Arduino sensors and computers. Thus students or researchers can do experiments to study a drying process. However, programming skills are needed.

\section{References}

1. Bani-Hani $E$, Abidoye $L$ (2016) Prediction of energy gains from Jordanian wind stations using artificial neural network. International Journal of Energy and Environmental Research 4: 26-41.

2. Al-Nassar W, Alhajraf S, Al-Enizi A, Al-Awadhi L (2005) Potential wind power generation in the State of Kuwait. Renewable Energy 30: 2149-2161.

3. Petkovic D, Arif M, Shamshirband S, Bani-Hani E, Kiakojoori D (2015) Sensorless estimation of wind speed by soft computing methodologies: a comparative study. Informatica 26: 1-16.
4. Abidoye L, Das D (2015) Artificial neural network modeling of scale dependent dynamic capillary pressure effects in two phase flow in porous media. Journal of Hydro Informatics 17: 446-461.

5. Abidoye L, Mahdi F (2014) Novel linear and nonlinear equations for the higher heating values of municipal solid wastes and the implications of carbon to energy ratios. Journal of Energy Technologies and Policy 4: 14-27.

6. Bani-Hani E (2017) MATLAB application for the selection of the best pipe series/ parallel arrangement in piping network. International Journal of Computer Applications 165: 0975-8887.

7. Lu Y, Bi C, Ye N, Bo H (2017) Auto-establishing simulation parallel manipulators with linear legs and auto-solving their workspaces by utilizing CAD variation geometry. International Journal of Computers and Applications 39: 1-14.

8. Russell M, Straub J (2016) Characterization of command software for an autonomous attitude determination and control system for spacecraft International Journal of Computers and Applications 38: 1-12.

9. César Ferández (2017) Improving student engagement on programming using app development with Android devices. Computer Applications in Engineering Education 25: 655-658.

10. Topcu EE (2017) PC-based control and simulation of an electro-hydraulic system. Computer Applications in Engineering Education 25: 706-718.

11. Das S, Pal S, Mitra M (2017) Arduino-based noise robust online heart-rate detection. Journal of Medical Engineering and Technology 41: 170-178.

12. Guo W, Wang L, Wang W (2015) Nonlinear platoon control of Arduino cars with range-limited sensors. International Journal of Control 88: 1037-1050.

13. De Paoli S, Storni C (2011) Produsage in hybrid networks: sociotechnical skills in the case of Arduino. New Review of Hypermedia and Multimedia 17: 31-52. 